\title{
Álvarez O.P., P. José. Diccionario Español Huarayo. Introducción y notas de María C. Chavarría Mendoza
}

Jaime Regan S.J.

\section{OpenEdition \\ Journals}

Edición electrónica

URL: http://journals.openedition.org/bifea/2950

DOI: 10.4000/bifea.2950

ISSN: 2076-5827

Editor

Institut Français d'Études Andines

Edición impresa

Fecha de publicación: 1 abril 2009

Paginación: 147

ISSN: 0303-7495

Referencia electrónica

Jaime Regan S.J., «Álvarez O.P., P. José. Diccionario Español Huarayo. Introducción y notas de María C. Chavarría Mendoza », Bulletin de l'Institut français d'études andines [En línea], 38 (1) | 2009, Publicado el 01 octubre 2009, consultado el 18 noviembre 2020. URL : http://journals.openedition.org/bifea/2950 ; DOI : https://doi.org/10.4000/bifea.2950

\section{(9) $(\mathbb{\Theta \Theta}$}

Les contenus du Bulletin de l'Institut français d'études andines sont mis à disposition selon les termes de la licence Creative Commons Attribution - Pas d'Utilisation Commerciale - Pas de Modification 4.0 International. 


\section{P. José Álvarez O.P. Diccionario Español Huarayo. Introducción y notas de María C. Chavarría Mendoza. Lima: Centro Pío Aza, 2008, 508 pps.}

Escribió esta obra como una ayuda para su trabajo misionero y en beneficio de futuros misioneros. Esta publicación es una versión completa del diccionario huarayo o ese eja escrito por el padre dominico José Álvarez, que apareció por partes en la desaparecida revista Antisuyo. Contiene 1381 entradas en castellano, en orden alfabético y aproximadamente 3200 palabras en huarayo. En cada entrada castellana da la palabra o palabras correspondiente(s) en la lengua indígena con algunos ejemplos del uso de la palabra y muchas veces un comentario sobre el tema esta.

La introducción de la lingüista María Chavarría presenta al autor y al pueblo huarayo, ahora llamado ese eja y que pertenece a la familia lingüística tacana. La comentarista indica que este trabajo no es un simple diccionario, sino una enciclopedia temática. Explica la notación que es próximo a un alfabeto moderno, y a la vez un aporte a la lingüística, a la dialectología y a la etnobotánica y etnozoología ese eja.

\section{Comentario}

Estas tres obras son una muestra de la preocupación de los misioneros en conocer y dar a conocer las culturas y lenguas de los pueblos donde trabajan. Han convivido y realizado la observación participante durante largos años y nos pueden ayudar a comprender de manaera detallada la vida de los pueblos amazónicos.

Una característica sobresaliente de estos y otros misioneros es su compromiso para con los pueblos donde viven y la defensa de sus derechos humanos y sus culturas. En el caso de los dominicos tienen una larga historia de defensa de los pueblos indígenas desde los debates entre los profesores de la Universidad de Salamanca y la obra de Bartolomé de las Casas hasta el presente. Otro personaje inspirador fue el dominico Fray Gaspar de Carvajal, cronista del recorrido por el río Amazonas de Francisco de Orellana. Fray Gaspar, después de su largo viaje, se convirtió en un gran defensor de los indígenas andinos en Argentina y Lima.

Esta tradición continúa. Es especialmente importante destacar la labor editorial del Centro Cultural Pío Aza de la orden dominica, sus eventos de difusión de la problemática amazónica y su museo etnográfico. Son aportes a la historia y culturas de una región desconocida para muchos peruanos. 